\title{
Retrofitting historical data in population studies: southern giant petrels in the Australian Antarctic Territory
}

\author{
Barbara Wienecke*, Rebecca Leaper, Ian Hay, John van den Hoff
}

Australian Antarctic Division, 203 Channel Highway, Kingston, Tasmania 7050, Australia

\begin{abstract}
The determination of the conservation status for a species at risk of extinction is based largely upon consistent change in the population size. In long-lived species, such as seabirds, longterm monitoring is required to establish the extent of the natural variability in a population and to detect true change. As studies spanning several generations within the same population are rare, researchers may turn to historically collected census information to expand the time frame of their studies. While in principle a valid approach, several limitations need to be considered to use historical information appropriately. Census information, collated from the 1950s to the present, of 3 populations of southern giant petrels Macronectus giganteus in the Australian Antarctic Territory (AAT) is used to highlight potential limitations inherent in historical data. We demonstrate the importance of census time and count units when investigating potential changes in populations. Published accounts indicate that the numbers of southern giant petrels in the AAT have decreased significantly since their discovery and that more recently some recovery has taken place. However, for 2 of the 3 populations we could not find evidence supporting a change.
\end{abstract}

KEY WORDS: Historical data · Population studies $\cdot$ Southern giant petrels $\cdot$ Australian Antarctic Territory

Resale or republication not permitted without written consent of the publisher

\section{INTRODUCTION}

Government departments responsible for the management of wilderness areas and wildlife populations rely on information about population trends when determining their management strategies. Population information is usually obtained from the published literature or from organisations that collate and summarise available data. Since populations fluctuate naturally, both management strategies and population data need to be reviewed regularly. In 2008, several key events drew attention to the conservation status of southern giant petrels Macronectus giganteus: (1) the Secretariat of the Agreement on the Conservation of Albatrosses and Petrels (ACAP) began compiling global assessments for each species listed under the agreement to establish the existing level of knowledge and to determine data gaps; (2) at a workshop in Cambridge,
UK, in May 2008, the Scientific Committee for Antarctic Research (SCAR) discussed global population data of southern giant petrels to examine a proposal to list this species as a 'specially protected species' under the Antarctic Treaty (1991); (3) the 'National recovery plan for albatrosses and giant petrels' of the Australian Government (Boland 2001) came under review.

In East Antarctica, there are only 4 known breeding locations of southern giant petrels; the easternmost colony occurs near the French research base Dumont $\mathrm{d}^{\prime}$ Urville $\left(66.76^{\circ} \mathrm{S}, 140.02^{\circ} \mathrm{E}\right)$. The other 3 are in the Australian Antarctic Territory (AAT) on islands near Australian research stations: the Frazier Islands $\left(66.23^{\circ} \mathrm{S}, 110.17^{\circ} \mathrm{E}\right)$ near Casey, Hawker Island $\left(68.63^{\circ} \mathrm{S}, 77.85^{\circ} \mathrm{E}\right)$ near Davis, and Giganteus Island $\left(67.58^{\circ} \mathrm{S}, 62.97^{\circ} \mathrm{E}\right)$ near Mawson (Fig. 1).

Currently, the International Union for the Conservation of Nature (IUCN) lists southern giant petrels as 


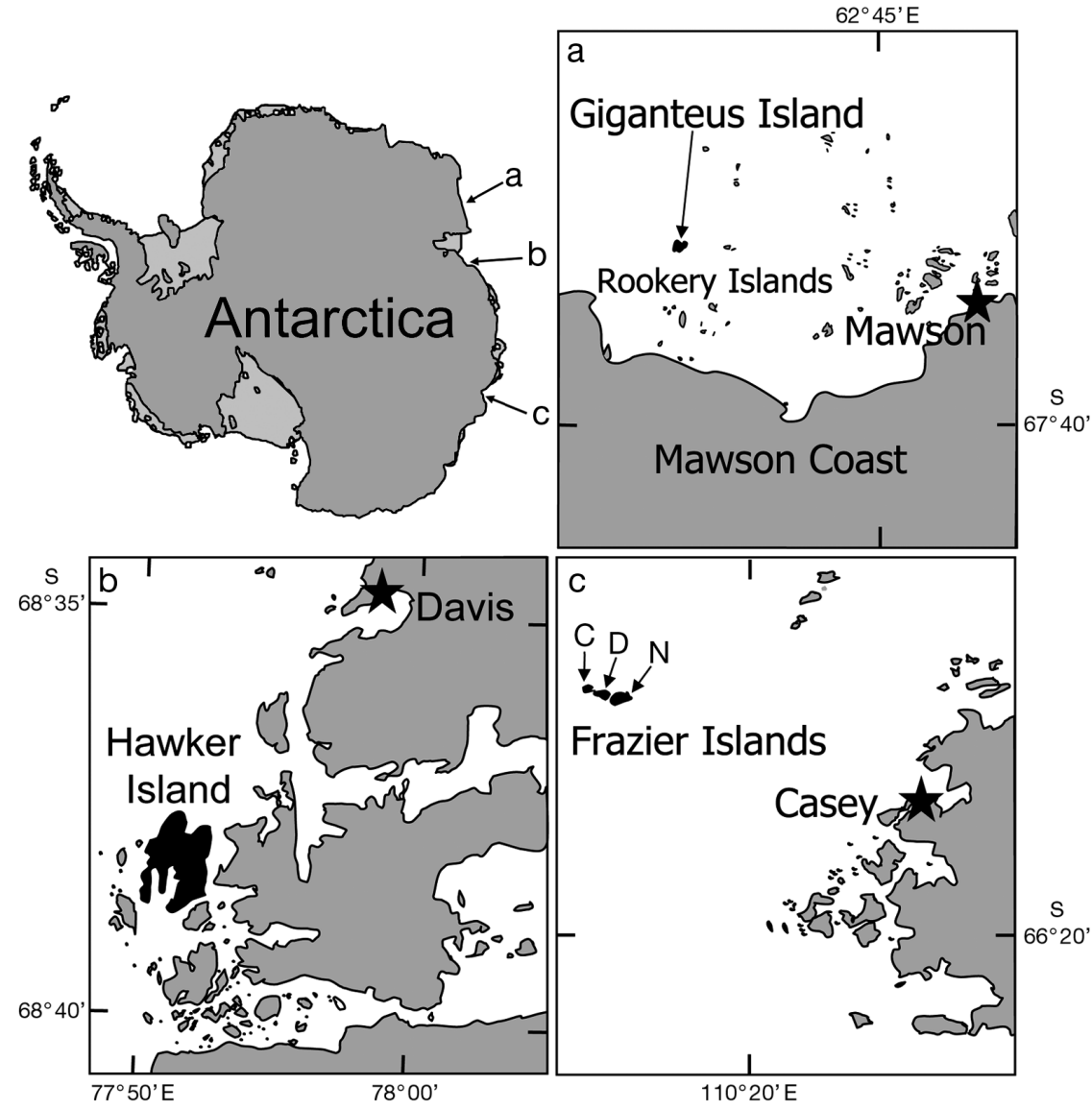

Fig. 1. Macronectes giganteus. $(\mathrm{a}-\mathrm{c})$ Breeding locations shown in black in the Australian Antarctic Territory (main map: land: dark grey; ice shelf: light grey). The 3 islands comprising the Frazier Islands are indicated in (c) (N: Nelly; D: Dewart; C: Charlton)

'Vulnerable' because many of their populations are thought to have decreased throughout their range (Stattersfield \& Capper 2000). In comparison, the Australian Environment Protection and Biodiversity Conservation Act 1999 (EPBC) lists the species as 'endangered' because, at the time of their listing, the populations in the AAT were thought to have decreased by between 30 and $92 \%$ since the 1950 s and 1960s (Woehler et al. 1990, 2003, Woehler \& Johnstone 1991, Boland 2001, Beeton et al. 2006). Human disturbance mainly associated with banding activities was considered the reason for the decreases, and measures, e.g. restricting access, were thought to have allowed some populations to stabilise or recover (e.g. Woehler et al. 2001, 2003). Creuwels et al. (2005), reanalysing data for the Frazier Islands (using the same data as Woehler et al. 2001, 2003), concluded that this population had essentially not changed from the first visitation and that human activities probably had not influenced this colony's status. These diverse conclusions indicate the potential difficulties encountered when interpreting historical data.
To determine the usefulness of historical information, both the methods and the timing of data collection have to be scrutinised carefully. A lack of scientific rigor and inappropriate timing of counts can compromise the data quality and can lead to erroneous conclusions. Here we use southern giant petrels in the AAT as a case study to illustrate potential limitations of historical information. The problems we encountered are not unique to this data set and will almost certainly apply to other data sets for this and other species. While southern giant petrels breed mainly on sub-Antarctic islands throughout the Southern Ocean and on the Antarctic Peninsula, examining their populations in the AAT is a useful test case because their populations here are small and, counting them should be relatively easy. We excluded census data on giant petrels at Australia's sub-Antarctic Macquarie and Heard Islands because these Islands are occupied by both northern (Macronectus halli) and southern giant petrels; the 2 species were not distinguished before 1966 (Bourne \& Warham 1966). When assessing how useful the AAT data are for analyses of population trends, we distinguish between estimates and systematic, repeated counts, and demonstrate the need to consider the data quality, as well as the dates of data collection, before engaging in analyses of long-term population changes. We show that retrofitting historical data to analyse population trends can be challenging, even misleading, and suggest ways to improve data collection in future monitoring programs for this and other species.

\section{MATERIALS AND METHODS}

Breeding chronology. The breeding chronology of southern giant petrels in the AAT is poorly understood because studies encompassing a whole breeding season have never been conducted. At Hawker Island, personnnel of the Australian National Antarctic Research Expeditions (ANARE) made 12 visits made between 24 September 1975 and 29 January 1976. This is the maximal number of visits to any of the 3 breeding locations in the AAT in one season. The presence 
of adults and yearlings was noted, as well as the number of occupied nests and eggs. Based on observations, the broad sequence of events during the breeding season is described below.

Southern giant petrels were present on the island from early August onwards. The birds in the colony sometimes included yearlings (very dark, evenly coloured plumage). In mid-September, the birds engaged in courtship, pair formation and copulation. Eggs were first seen in late October. In early November, birds sat tight on their nests when approached closely and eggs were seen in some nests. Incubation proceeded throughout December; whether eggs were still being laid is unknown. By mid- to late-December, eggs had not hatched. By mid-January, about $75 \%$ of chicks had hatched but some eggs remained. In late March, chicks were at various stages of losing their down. In early April, chicks were almost fledged but not yet able to fly. Southern giant petrel chicks banded earlier in a season were sometimes resighted away from the island in mid- to lateApril. In the 1975-76 season, the number of adults in the colony ranged from 26 on 8 October to 64 on 8 November, but the maximal number of eggs observed was 27 .

Data gathering. Initially the published literature was searched for census information. As inconsistencies between publications became apparent with regard to the count data, we sought to verify wherever possible information from original field notes stored at the Australian Antarctic Division (AAD). We also attempted to contact in person the original collators and authors of the information. However, some notes were collated by different personnel within a single breeding season and their names were not always given. We also searched AAD permit records, all available station and field trip reports, biology logs and any other sources that may have contained information. Finally, we obtained banding records of southern giant petrels from the Australian Bird and Bat Banding Scheme (ABBBS, Department of Water, Heritage and the Arts, Canberra) and the North American Bird Banding Program (Bird Banding Laboratory, US Geological Survey). ABBBS data were useful to confirm other reports. Where only banding records but no further data were available, the information was deemed incomplete because we could not verify that all chicks present were banded.

Data evaluation. All information was archived electronically in a simple database, noting (where available) the observation date, counts, count units (e.g. adults, nest, chicks), count methods (ground-based or from the air), whether or not they could be verified from the original notes, and any comments made in the field notes or log books or by researchers who were contacted directly. This newly collated dataset will be made available to the Secretariat of ACAP in Hobart, Tasmania, and the AAD's Data Centre (AADC).
Once the available information was compiled we regarded a count as valid if (1) the count date recorded included at least month and year, (2) count units were clearly stated, (3) data reported in the published literature could be verified from original log books or at least one other source, (4) they were ground counts, and (5) data were gathered systematically (e.g. repeated counts) rather than just broad estimates of abundance. Aerial counts were not included because no photographs were taken and the number of nests was only estimated. The only confirmed overflights occurred in 1964 (Dewart Island), 1972 (Charlton Island) and in 2007 (Giganteus Island). The latter confirmed earlier ground observations while the former two were the only estimates of the number of birds/nests for these seasons (see Table S3d in Supplement, available at www.int-res.com/articles/ suppl/n008p157_app.pdf). Information not meeting these criteria was considered to be anecdotal and not useful for analyses of population trends. The detailed information is summarised by location in Tables S1 to S3 (available at www.int-res.com/articles/suppl/ n008p157_app.pdf).

We stress that we did not interpret the information in any way. For example, if a logbook entry stated that ' $x$ ' number of adults were counted we did not assume that ' $\mathrm{x}$ ' equaled the number of breeding pairs. Verified data were plotted separately by count unit and month.

The Frazier Islands are unique in East Antarctica because they comprise 3 small islands all of which are occupied by southern giant petrels. Information from these islands was recorded as counts by island because the number of islands visited varied in any one season. Because of the poor understanding of the variability in the breeding chronology of southern giant petrels in the AAT, we present data by calendar month rather than by breeding stage.

\section{RESULTS}

\section{Data integrity}

Not all previously published information for southern giant petrels in the AAT could be verified from original sources. Some reports were probably never submitted to the AAD's record keeping facilities. When examining the usefulness of the data for trend analyses several problems became apparent: (1) count units varied (e.g. breeding adults, juvenile birds, occupied nests, chicks), (2) count dates varied widely or were not recorded, (3) in the early years 'counts' were often simple estimates of abundance, (4) the methods applied varied, usually without any measure for accuracy, (5) the number of chicks banded on any occasion did not always include all chicks present, (6) there were dis- 
parities between what was counted (e.g. occupied nest sites) and what was later reported (e.g. breeding pairs), (7) counts were frequently made by inexperienced personnel, and (8) count reports by different authors on the same data varied sometimes (see Supplement). The reasons for these differences were unclear. In the following paragraphs we summarise the results for each breeding location separately before examining whether population trend analyses are possible for the 3 AAT locations.

\section{Giganteus Island}

Southern giant petrels at Giganteus Island (Fig. 1) were first sighted on 10 August 1956. Since then, the colony was visited in 22 of the 51 yr from 1956 to 2007 (Table S1). Valid counts of the number of birds or the number of occupied nests were conducted in 14 of the 22 yr (Table S1a). Multiple visits during the same season were made in only 3 yr $(1967,1972,1978)$ giving a total of 18 valid counts. However, 3 surveys (10 August 1956, 3 and 19 September 1972) were undertaken outside the breeding season. For a further 8 visits only incomplete information was available and the count units were unclear (Table S1b).

All variables counted (adults, nests, eggs) peaked in the late 1950s to early 1960s and had decreased by 1965. Since then, the number of incubating birds has remained low but relatively stable. The number of adults was always noticeably higher than the number of occupied nests or eggs. Egg numbers were always lower than the number of adults in the colony; the maximal number of eggs was 18 on 29 November 1959 (Table S1a). The most dramatic decrease in egg production occurred from 1962 ( $\mathrm{n}=14$ ) to 1965 ( $\mathrm{n}=4)$; egg numbers appear to have remained low but relatively unchanged at 1 to 4 eggs per annum since then.

\section{Hawker Island}

The southern giant petrel colony at Hawker Island (Fig. 1) was discovered in December 1963 (D. Lugg pers. comm.) and has become the most frequented giant petrel colony in the AAT. Thirty-nine visits took place in the 44 yr from 1963 to 2007 (12 in 1975-76). We verified 36 (Table S2a) but 7 were either nonsystematic or there were uncertainties about their accuracy and completeness (Table S2b). Thus, 29 valid counts were conducted; of the 7 counts made during laying or incubation (November, December) 5 occurred in 1975. Three November counts of adults were made in 1974, 1975 and 1976. Occupied nests were counted only in 5 years.
We validated 17 counts made during chick rearing: 5 counts occurred in January (2 in 1976), 5 in February, 4 in March, and 2 in April. Breeding success could not be estimated as the numbers of breeders and of chicks were not available for any season (Table S2a). The counts conducted in 1974 (April, November) and 1976 (January, November) fall into different breeding seasons.

\section{Frazier Islands}

This island group comprises 3 small islands: Nelly, Dewart and Charlton (Fig. 1). Nelly Island was first visited in late January 1956; Dewart and Charlton islands were not visited. Four separate breeding colonies of southern giant petrels were discovered and $\sim 250$ nests, both occupied and unoccupied, were estimated to be on the island. Chicks were present but not counted (J. Bunt pers. comm.).

Nelly Island was surveyed 27 times in 20 of $45 \mathrm{yr}$ from 1956 to 2001 (Table S3a,b). Three visits per season were made in 1959, and 2 visits occurred in 1977 and 1983. We validated 13 counts, of which 5 were made during laying/incubation (November-December) and 8 during the chick rearing period (JanuaryMarch) (Table S3a). The first systematic count of occupied nests during incubation was made at Nelly Island in November 1983, and 4 more counts are available for December 1989, 1997, 1998 and 2001. The visits during chick rearing occurred in January $(\mathrm{n}=10)$, February ( $\mathrm{n}=4)$ and March $(\mathrm{n}=4)$.

At Dewart Island, chicks were banded in 7 seasons between 1970 and 1990. Chick numbers varied, as did the month during which nestlings were banded. Systematic counts of occupied nests commenced only in 1989 and 4 counts (1989, 1997, 1998 and 2001) were conducted over the next 12 years (Table S3c).

Charlton Island was once thought to be devoid of southern giant petrels. During an overflight in 1972, some nests were sighted. Six years later, the first banding expedition was conducted and 6 giant petrel chicks were marked. Chicks were again banded in 1979 (n = 5) and in $1986(n=9)$. Occupied nests were surveyed 4 times from 1989 to 2001 (Table S3c).

All 3 islands were visited within the same breeding season on 7 occasions (January 1978, November 1983, December 1989, 1997, 1998, 2001, and March 1999). Again, most visits occurred during various phases of the chick rearing period.

\section{Population trends}

Information has been collected, albeit intermittently, at the colonies of southern giant petrels in the AAT for 
$>50$ yr. However, when summarising the systematically gathered data, 3 problems become clear: (1) counts were conducted at different times during the breeding season, (2) there are gaps of up to $20 \mathrm{yr}$ between consecutive counts, and (3) different count units were employed.

For Giganteus Island, counts of occupied nests (November/December) provide some evidence that the population status changed before 1965. The highest numbers of occupied nests (up to 23) were seen in November 1958, 1959 and 1962. Since then, no more than 4 occupied nests were counted. However, since 1965, the population has remained marginal but stable.

At Hawker Island, there is insufficient information to evaluate potential population changes (Table S2a). Similarly at the Frazier Islands, chick counts were the most numerous and, hence, the majority of counts are not useful for the analysis of population dynamics. Valid counts of adults at both Nelly and Dewart islands are available only for recent years and are too few for any trend assessment (Table S3a,c).

\section{DISCUSSION}

\section{General observations on population studies and historical data}

One of the most important tasks in assessing the risk of extinction of a long-lived species is to evaluate the available information on population abundance (local and global) and its change over time. Population size fluctuates naturally at short and long temporal scales. Hence, the extent of this variability must be determined over the long term. Ideally studies on long-lived species examine variability on a decadal (Thompson \& Grosbois 2002). A sustained decrease may indicate that a population is at risk.

The life histories of seabirds are characterised by long life expectancy, delayed sexual maturity and low annual reproductive output. Thus, changes in population structures may be noticeable only after many years. Seabird populations can fluctuate substantially in response to environmental variability (e.g. Thompson \& Grosbois 2002) such as, for example, changes in prey availability and climate (e.g. Croll et al. 2006, Polland et al. 2008). Monitoring studies should then encompass a minimum of 1 or, preferably, 2 generations (Nisbet 1989, Thompson \& Grosbois 2002). However, when monitoring programs rely solely on abundance estimates, the cause of a population change may occur well before changes in the population size become apparent (Purcell 2002).

Given the need for long-term data (Pienkowski 1991), historical information can provide some valu- able insights (see Reid \& Huin 2008), and researchers may include historical information to extend the period across which to determine population trends (e.g. Micol \& Jouventin 2001, Weimerskirch et al. 2003, Sander et al. 2007). This approach is appropriate as long as the historical data are based on comparable methods and ideally were collected for the purpose of studying population trends (e.g. Bradley et al. 1999, Sander et al. 2007, Reid \& Huin 2008).

\section{Southern giant petrels in the AAT}

In the early years, the major scientific objective of studies on southern giant petrels in the AAT was not to monitor population trends but to determine the species' dispersal range, especially that of fledglings (see Sladen et al. 1968), based on banding returns. February was deemed to be the best time for the work as the chicks were largely unattended by their parents, were still unable to fly but their tarsi had attained their maximal girth and could receive bands. However, difficulties in accessing the islands because of sea-ice or inclement weather could delay the visits until March or April. Thus, the timing of chick banding efforts varied between years.

The information for southern giant petrels in the AAT is confounded by a poor understanding of key events in their breeding chronology. From a single visit during incubation, we can neither confidently determine the total number of eggs laid nor can we forecast breeding success without information on fledging success, which is highly variable (e.g. 38 to $100 \%$ in the Falkland Islands) (Reid \& Huin 2008). Similarly, the total number of breeders cannot be calculated retrospectively from a single visit any time during the approximately 4 mo chick rearing period because there is no information on how many eggs were abandoned or lost to skuas Catharacta spp. At Possession Island, Crozet Archipelago, and at Signey Island, South Orkney Islands, most eggs were lost relatively early in the season (Conroy 1972, Voisin 1988).

The few available long-term studies for southern giant petrels highlight the complicated nature of their breeding regime. At Bird Island, South Georgia $\left(54.76^{\circ} \mathrm{S}, 37.00^{\circ} \mathrm{W}\right)$, southern giant petrels were breeding every season, but 27 to $34 \%$ of individuals banded in 1978-79 were observed as non-breeders in the next 2 seasons (Hunter 1984). Furthermore, small colonies may change locations between breeding seasons ( $T$. Reid pers. comm.). This variability, plus the fact that the early 'counts' were not part of an ongoing study on population trends, supports the need for a conservative approach to historical information. 
Previously, the disparate nature of the AAT count data had been acknowledged but was considered a minor limitation (Woehler et al. 2003). Historical counts were seen as a useful 'baseline' from which population trends could be determined. An analysis of the Hawker Island data, for example, included rough estimates, such as 40 to 50 nest sites in December 1963 and 150 nests in December 1970 (Woehler et al. 2003). Also, the numbers of chicks counted during different months were presented as the numbers of breeding pairs. As equal weighting was given to all information regardless of the count dates, the analysis then showed that the southern giant petrel population at Hawker Island decreased from 90 breeding pairs in 1970-71 (based on a rough estimate) to 10 in 1984 (Woehler et al. 2003 stated the year as 1983 probably because the original data referred to the split year 1983-84). However, retrieval of the original field record and a conversation with the data collator indicated that '10' was the number of chicks banded in 1984 but that more 'nests' were present (K. Green pers. comm.). It is unknown how many chicks had hatched or had perished or how many eggs were lost earlier on. Finally, the suggested decline was apparently followed by a population increase in the late 1980s (Woehler et al. 2003). However, the count units (and time) had changed and were now more representative of the size of the breeding population, as occupied nests rather than chicks were counted.

In comparison, Creuwels et al. (2005) noted that the early counts for the Frazier Islands were problematic and concluded that some of the observed trends could be attributed to inconsistencies in census methods. We agree with Creuwels et al. (2005) that the population of southern giant petrels at the Frazier Islands has probably remained relatively stable since occupied nest counts were made in recent years. But we stress that no defendable claims can be made with regard to population trends dating back to when the islands were first visited as insufficient reliable counts are available. Furthermore, any implied population change may be due to natural variability (Creuwels et al. 2005).

Our evaluation of the historical data showed that many of the early 'baseline' counts were inaccurate and unsuitable for population trend analyses. Considering the timing and separating the count units, there is a difference between the number of adults present and the number of occupied nests; the latter tends to be lower than the former. Since both timing and the choice of count unit have implications for the outcome of any potential trend analysis, count units should always be kept separate. Problems can also arise where the time span of suitable counts falls well below the duration of one generation (see Nisbet 1989). For example, at Hawker Island, data are available only for 3 (adults) and 4 (occupied nests) consecutive years.
Even if these counts were combined, the gap between the second last and last count is $22 \mathrm{yr}$.

Similar problems apply to the Frazier Islands data, with the added complication that southern giant petrels occupy 3 islands. As not all islands were visited on each occasion, pooling all information per season regardless of the number of islands surveyed strongly influenced previous trend analyses.

The breeding population of southern giant petrels at Giganteus Island is different from the other two. It is the smallest of the AAT colonies and has the most solid long-term data set with 10 counts of occupied nests mainly from late October or November from 1958 to 2007. It is also the only colony where the breeding population decreased about 4 decades ago. The reasons for this are unknown but human disturbance seems unlikely because the island was only visited intermittently. During the period of population change, visits occurred during 5 of the $9 \mathrm{yr}$ from 1956 to 1965; the 1956 visit in August was outside the breeding season. In November 1958, 1 juvenile plus 26 yearlings were banded and a further 12 birds of 1 yr or older were ringed in November 1959. In November 1962 (the next visit), 49 birds were seen. While banding is highly intrusive, it probably would not cause permanent desertion because the birds banded in 1958 were not yet of breeding age; the 12 marked a year later were all banded on the same day and were probably nonbreeding. Multiple visits in the same season were exceptional and all occurred after the decrease: 2 visits were made in 1967, 3 in 1972 and 5 in 1978. Limited access to the island from the sea-ice resulted in few visits, usually early in the breeding season. Once the sea-ice became unstable, the Rookery Islands were inaccessible until the sea froze again in April/May, when the breeding season of the southern giant petrels had come to an end; boats were not used until the late 1980s (J. Copson pers. comm.).

The reported decline of the colony from 24 nests in 1956 to 2 in 1985 (Woehler \& Johnstone 1991) is problematic as the 1956 nest count took place in August and was not a true representation of the breeding population. Since only 8 birds were counted, most if not all nest sites reported were unoccupied. Moreover, all birds were darkly coloured and were probably yearlings. While a decrease certainly occurred at Giganteus Island, it is difficult to determine the onset or the time span over which it occurred. The maximal number of eggs $(n=13)$ was reported in 1962. From 1965 to 1977, the island was visited only during 5 years when peak laying had probably not yet occurred. As the number of occupied nests has remained low $(\leq 4)$ since the mid-1960s, the colony should be considered marginal but stable.

Interestingly, from the late 1950s until 1993 husky dogs were kept at Mawson Station. To feed the 20+ 
dogs, 20 or more Weddell seals Leptonychotes weddellii were shot each spring. The practice was stopped in the early 1980s (T. Maggs pers. comm.). The remnants of the seal carcasses were left on the ice, providing highly accessible food for scavenging birds such as giant petrels and skuas (D. Lugg pers. comm.). Even today, large numbers of southern giant petrels, exceeding the number of birds known to breed at Giganteus Island, are observed where seal carcasses are available (e.g. van den Hoff \& Newberry 2006). In the 1950s and 1960s, the increased food supply was still present, while the numbers of southern giant petrels decreased. Thus, food supply may not have contributed to the decline of this population.

The population of southern giant petrels at Giganteus Island comprised very few birds for $>40 \mathrm{yr}$. We have no knowledge about their breeding success, recruitment rates or migration to or from other colonies. Increased snow cover could have reduced the quality of the breeding habitat forcing the birds to move elsewhere; perhaps disease played a role, although dead adults or juveniles were never reported. Quintana et al. (2006) suggested that the positive trend for populations of southern giant petrels in Argentina may be related to increases in the nearby penguin, elephant seal and sea lion colonies. Compared to other colonies of southern giant petrels, the food supply near Giganteus Island today appears limited. A number of Adélie penguin Pygoscelis adeliae colonies are nearby but these are guarded by Antarctic skuas Catharacta maccormicki.

\section{Conclusions and future work}

Historical data need to be analysed with care if the timing of data collection was variable, the count methods and units differed, or the purpose of the counts was not commensurate with population studies. Differences in skills and experience among observers also need to be considered as these factors alone can influence the outcome of a visual census. Given the disparate nature of both count data and methods in southern giant petrel studies in the AAT, we conclude that no significant change to the numbers breeding at Hawker Island and the Frazier Islands can be robustly demonstrated. However, there appears to have been an initial marked decrease at Giganteus Island followed by a long period (40 yr) of relative stability.

Although southern giant petrels have been the subject of research in East Antarctica for decades, their basic breeding biology is poorly understood. Longterm, systematic research is needed to establish a robust data set to assess (1) the population status of the birds both at local (i.e. breeding sites) and regional scales (East Antarctica), (2) whether nests are occupied intermittently and whether individuals take leave from breeding, and (3) the extent of the natural fluctuations in population size and inter-annual variability in the timing of major events in the breeding cycle.

Ideally, standardised methods and nomenclature (see Creuwels et al. 2005) should be employed wherever populations are studied, and information should be collected on abundance and, if possible, on breeding success. To estimate the size of the breeding population, ideally the number of incubating birds is counted as close as possible to the time when the majority of eggs have been laid (peak laying). If the time of peak laying is unknown, counts should be conducted at approximately the same time of year.

Given the concern about disturbance to breeding southern giant petrels, non-invasive new technologies should be employed wherever possible. We recommend the establishment of a remote monitoring program, as used for Adélie penguins, using automated cameras (Newbery \& Southwell 2009) at accessible colonies. To minimise disturbance, deployment of equipment should occur before breeding commences and retrieval of gear after fledging. Images may provide insights into the timing of some key events during the breeding season. Images also have the advantages that they are archival, thus repeat counts can be carried out and information is verifiable in future. Since policy makers and wildlife managers now have to consider the issue of climate change, well-structured, long-term population studies of long-lived species are more important than ever.

Acknowledgments. We thank the staff of the library and the records store at the Australian Antarctic Division for their help in finding historical materials, and are grateful for the conversations with former expeditioners and their willingness to share information. We thank David Drynan (Australian Bird and Bat Banding Scheme) and the staff of the Patuxent Wildlife Research Centre, Laurel, Maryland (Bird Banding Laboratory, US Geological Survey), for making available the banding data. We also thank L. Emmerson and G. Robertson for reviewing earlier versions of this work and T. Reid and an anonymous referee for their helpful comments.

\section{LITERATURE CITED}

Antarctic Treaty (1991) Annex V to the Protocol on Environmental Protection to the Antarctic Treaty Area Protection and Management. Recommendation Antarctic Treaty Consultative Meeting XVI-10, Bonn

Beeton RJS, Buckley KI, Jones GJ, Morgan D, Reichelt RE, Trewin D (2006) Australia State of the Environment 2006. Australian State of the Environment Committee. Independent report to the Australian Government Minister for the Environment and Heritage, Department of the Environment and Heritage, Canberra

Boland C (2001) National recovery plan for albatrosses and giant petrels. Environment Australia, Canberra 
Bourne WRP, Warham J (1966) Geographical variation in the giant petrels of the genus Macronectes. Ardea 54:45-67

Bradley JS, Gunn BM, Skira IJ, Meathrel CE, Wooller RD (1999) Age-dependent prospecting and recruitment to a breeding colony of short-tailed shearwaters Puffinus tenuirostris. Ibis 141:277-285

Conroy JWH (1972) Ecological aspects of the biology of the giant petrel, Macronectes giganteus (Gmelin), in the maritime Antarctic. Br Antarct Surv Sci Rep No 75. British Antarctic Survey, Cambridge

Creuwels JCS, Stark JS, Woehler EJ, van Franeker JA, Ribic CA (2005) Monitoring of southern giant petrel Macronectes giganteus population on the Frazier Islands, Wilkes Land, Antarctica. Polar Biol 28:483-493

Croll DA, Demer DA, Hewitt RR, Jansen JK, Goebel ME, Tershy BR (2006) Effects of variability in prey abundance on reproduction and foraging in chinstrap penguins (Pygoscelis antarctica). J Zool 269:506-513

Hunter S (1984) Breeding biology and population dynamics of giant petrels Macronectes at South Georgia (Aves: Procellariiformes). J Zool 203:441-460

Ingham SE (1959) Banding of giant petrels by the Australian National Antarctic Research Expeditions, 1955-1958. Emu 59:189-200

Micol T, Jouventin P (2001) Long-term population trends in seven Antarctic seabirds at Pointe Géologie (Terre Adélie). Polar Biol 24:175-185

Newbery K, Southwell C (2009) An automated camera system for remote monitoring in polar enviroments. Cold Reg Sci Technol 55:47-51

Nisbet ICT (1989) Long-term ecological studies of seabirds. Colon Waterbirds 12:143-147

Pienkowski MW (1991) Using long-term ornithological studies in setting targets for conservation in Britain. Ibis 133:62-75

Polland V, Barbraud C, Weimeskirch H (2008) Combined effects of fisheries and climate on a migratory long-lived marine predator. J Appl Ecol 45:4-13

Purcell KL (2002) Abundance and productivity of birds over an elevational gradient. In: Verne J (ed) Proceedings of a symposium on the Kings River sustainable forest ecosystem project: progress and current status. USDA Forest Serv Gen Tech Rep PSW-GTR-183, p 121-131

Quintana F, Punta G, Copello S, Yorio P (2006) Population status and trends of southern giant petrels (Macronectes giganteus) breeding in North Patagonia, Argentina. Polar

Editorial responsibility: Brendan Godley,

University of Exeter, Cornwall Campus, UK
Biol 30:53-59

Reid TA, Huin N (2008) Census of the southern giant petrel population of the Falkland Islands 2004/05. Bird Conserv Int 18:118-128

Sander M, Balbão TC, Polito MJ, Costa ES, Bertolid Carneiro AP (2007) Recent decrease in chinstrap penguin (Pygoscelis antarctica) populations at two of Admirality Bay's islets on King George Island, South Shetland Islands, Antarctica. Polar Biol 30:659-661

Sladen WJL, Wood RC, Monaghan EP (1968) The USARP bird banding program, 1958-1965. In: Austin OL (ed) Antarctic bird studies. Antarct Res Ser 12:213-262

Stattersfield AJ, Capper DR (2000) Threatened birds of the world. Lynx Ediciones, Barcelona, and BirdLife International, Cambridge.

Thompson PM, Grosbois V (2002) Effects of climate variation in seabird population dynamics. Sci World J 1:50-52

van den Hoff J, Newberry K (2006) Southern giant petrels Macronectes giganteus diving on submerged carrion. Mar Ornithol 34:61-64

Voisin JF (1988) Breeding biology of the northern giant petrel Macronectes halli and the southern giant petrel M. giganteus at Île de la Possession, Îles Crozet, 1966-1980. Cormorant 16:65-97

Weimerskirch H, Inchausti P, Guinet C, Barbraud C (2003) Trends in bird and seal populations as indicators of a system shift in the Southern Ocean. Antarctic Science 15:249-256

Woehler EJ, Johnstone GW (1991) Status and conservation of seabirds of the Australian Antarctic Territory. In: Croxall JP (ed) Seabird status and conservation: a supplement. International Council for Bird Preservation, Tech Pub 11:279-308

Woehler EJ, Martin MR, Johnstone GW (1990) The status of southern giant petrels Macronectes giganteus at the Frazier Islands, Wilkes Land, East Antarctica. Corella 14:101-106

Woehler EJ, Cooper J, Croxall JP, Fraser WR and others (2001) A statistical assessment of the status and trends of Antarctic and Subantarctic seabirds. SCAR, Cambridge

Woehler EJ, Riddle MJ, Ribic CA (2003) Long-term population trends in southern giant petrels in East Antarctica. In: Huiskes AHL, Gieskes WWC, Rozema J, Schorno RML, van der Vies SM, Wolff WJ (eds) Antarctic biology in a global context. Backhuys Publishers, Leiden, p 290-295

Submitted: December 19, 2008; Accepted: March 31, 2009 Proofs received from author(s): June 23, 2009 